\title{
FEATURE
}




\section{Pediatric ENT Complaints: An Update}

Melanie A. Weller, MD; Joel M. Clingenpeel, MD, MPH, MS.MEdL

\section{This review highlights the diagnosis and management of the three most common causes of pediatric otolaryngologic complaints seen in the ED.}

A mong all of the causes of ear, nose, and throat (ENT) complaints, acute otitis media (AOM), bacterial sinusitis, and streptococcal pharyngitis (SP) are the most common infections prompting pediatric presentation to the ED. Through a series of case scenarios, along with key questions to help guide the clinician's workup, this review covers the proper evaluation and management of pediatric ENT complaints.

\section{Case Scenario 1}

A 13-month-old girl presented to the ED with a 1-day history of fever and runny nose. According to her parents, the child had been continually pulling on her ears in apparent discomfort. During historytaking, the parents further informed the emergency physician (EP) that the patient started daycare 4 months earlier and had two elementary school-aged siblings. The patient's medical history was significant for otitis media, but the parents stated she had not been on antibiotics for over 4 months.
On physical examination, the patient's vital signs were: blood pressure (BP), 75/50 $\mathrm{mm} \mathrm{Hg}$; temperature (T), $101.3^{\circ} \mathrm{F}$; slight tachycardia; and normal age-adjusted respiratory rate (RR). Oxygen saturation was $100 \%$ on room air. The lungs were clear to auscultation and heart sounds were normal and without murmur. The otolaryngologic examination revealed copious yellow discharge from both nostrils, non-erythematous posterior oropharynx, and erythema to the right tympanic membrane (TM).

Questions to Guide the Work-Up: (1) What physical examination findings should be present for accurate diagnosis of otitis media? (2) Will this patient require antibiotics immediately, or is a "wait-and-see" approach indicated? (3) If treatment with antibiotic therapy is warranted, what are the appropriate therapeutic regimen and duration of therapy?

\section{Otitis Media}

Acute otitis media is one of the most common presentations in young children. Defined as the rapid onset of signs and

Dr Weller is a fellow in pediatric emergency medicine, Eastern Virginia Medical School/Children's Hospital of The King's Daughters, Norfolk. Dr Clingenpeel is the fellowship director of pediatric emergency medicine; and associate professor of pediatrics, Eastern Virginia Medical School/Children's Hospital of The King's Daughters, Norfolk.

Authors' Disclosure Statement: The authors report no actual or potential conflict of interest in relation to this article.

DOI: 10.12788/emed.2017.0005 
symptoms of middle ear inflammation, in conjunction with middle ear effusion (MEE), AOM can develop secondary to a viral or bacterial infection. It is estimated that more than $80 \%$ of the pediatric population will experience at least one episode of AOM by age 3 years. ${ }^{1-3}$

Risk factors for AOM include upper respiratory infection (URI), daycare attendance, siblings, parental smoking, and formulafeeding versus breastfeeding. The patient's history may include rapid-onset otalgia, fever, irritability, anorexia, and concurrent URI symptoms, as well as other nonspecific symptoms (eg, ear rubbing and/or pulling, crying, changes in behavior and sleep patterns). ${ }^{2-4}$ In general, otalgia and ear-rubbing in the nonverbal patient seem to have the best predictive value for $\mathrm{AOM}^{3}$

\section{Signs and Symptoms}

A normal TM should be translucent and pearly gray, with visible landmarks of the manubrium of malleus and pars flaccida. A TM that is bulging, cloudy, and immobile is the most consistent finding in AOM, with bulging having a specificity of $97 \%$. Redness of the tympanic membrane is not a useful predictor of AOM as this finding is noted in upward of $30 \%$ of pediatric patients on general examination but in $<1 \%$ of AOM diagnoses in the absence of a bulging TM.

\section{Diagnosis}

Pneumatic otoscopy is the gold standard for diagnosing for MEE; however, this examination can be difficult in younger, often uncooperative, patients. A TM that does not perceptibly move with either positive or negative insufflation pressure greatly enhances the diagnostic accuracy for MEE over the use of visible eardrum characteristics alone. ${ }^{2-5}$

Acute otitis media is a clinical diagnosis and does not require imaging studies or laboratory evaluation unless more serious processes, such as skull fracture, mastoiditis, or intracranial abscess, are being considered. ${ }^{2,3}$

\section{Treatment and Management}

Analgesia. The first step in managing patients with AOM is to provide analgesia. In most cases, acetaminophen in patients over 2 months of age, or ibuprofen in patients over 6 months of age, are adequate choices for managing pain. When either of these analgesics is administered in the clinic/ED setting, patients should be monitored to assure adequate pain relief prior to discharge.

While topical agents such as combination antipyrine-benzocaine suspensions were commonly given in the past to alleviate the pain associated with AOM, there are limited data to support their effectiveness. As such, in July 2015, the US Food and Drug Administration ordered manufacturers to halt production on these unapproved prescription products., ${ }^{3,46}$ There are also no randomized controlled trials (RCTs) to support the use of decongestants or antihistamines for resolution of AOM or otalgia. ${ }^{3,7}$

Antibiotic Therapy. The most common bacteria associated with AOM are Streptococcus pneumonia, nontypeable Hemophilus influenza, and Moraxella catarrhalis. In $30 \%$ of patients, the causative etiology is viral. When the decision is made to treat AOM, high-dose amoxicillin is still considered the first-line treatment, despite ever evolving susceptibilities of bacteria. Alternate therapies include amoxicillinclavulanate, azithromycin, cefdinir, ceftriaxone, and sulfamethoxazole-trimethoprim; however, treatment with azithromycin or sulfamethoxazole-trimethoprim should be reserved for patients who have a history of anaphylactic reaction to penicillin (Table 1).

When a child is noted to have been treated with amoxicillin within a 30-day period or who has concurrent conjunctivitis, amoxicillin-clavulanate is considered the first-line treatment. ${ }^{2-4,7,8}$ The current American Academy of Pediatrics (AAP) guidelines recommend 10 days of antibiotic therapy for children younger than age 2 years, and 5 to 7 days for children older 
Table 1. Recommended Antibiotic Therapy for Acute Otitis Media and Acute Bacterial Sinusitis $2-4,7,10,12$

\begin{tabular}{|c|c|c|c|}
\hline Drug & Dose & Maximum Dosage & Notes \\
\hline Amoxicillin & $\begin{array}{l}80-90 \mathrm{mg} / \mathrm{kg} / \mathrm{d} \\
\text { divided twice a day }\end{array}$ & 2,000 mg per dose & \\
\hline $\begin{array}{l}\text { Amoxicillin- } \\
\text { clavulanate }\end{array}$ & $\begin{array}{l}80-90 \mathrm{mg} / \mathrm{kg} / \mathrm{d} \\
\text { (amoxicillin component } \\
\text { divided twice a day) }\end{array}$ & $\begin{array}{l}\text { 2,000 mg per dose } \\
\text { (amoxicillin component) }\end{array}$ & $\begin{array}{l}\text { Use } 14: 1 \\
\text { amoxicillin:clavulanate ratio } \\
\text { (ES-600 suspension) }\end{array}$ \\
\hline Cefdinir & $\begin{array}{l}14 \mathrm{mg} / \mathrm{kg} / \mathrm{d} \\
\text { daily or divided twice a day }\end{array}$ & $600 \mathrm{mg} / \mathrm{d}$ & $\begin{array}{l}\text { May cause dark red stool } \\
\text { (resembling melena), particularly } \\
\text { in infants on iron-fortified } \\
\text { formulas }\end{array}$ \\
\hline Azithromycin & $\begin{array}{l}10 \mathrm{mg} / \mathrm{kg} / \mathrm{d} \text {, day } 1 \\
5 \mathrm{mg} / \mathrm{kg} / \mathrm{d} \text {, days } 2-5\end{array}$ & $\begin{array}{l}500 \mathrm{mg} \text {, day } 1 \\
250 \mathrm{mg} \text {, days } 2-5\end{array}$ & \\
\hline $\begin{array}{l}\text { Sulfamethoxizole- } \\
\text { trimethoprim }\end{array}$ & $\begin{array}{l}\text { 8-12 } \mathrm{mg} / \mathrm{kg} / \mathrm{d} \\
\text { trimethoprim component } \\
\text { divided twice a day }\end{array}$ & $\begin{array}{l}160 \text { mg per dose } \\
\text { trimethoprim component }\end{array}$ & \\
\hline \multirow[t]{2}{*}{ Ceftriaxone } & $\begin{array}{l}50 \mathrm{mg} / \mathrm{kg} \text { intramuscularly for } \\
1 \text { day, with maximum of } 1,000 \\
\mathrm{mg} \text { per dose }\end{array}$ & $1,000 \mathrm{mg}$ & \multirow{2}{*}{$\begin{array}{l}\text { Acute otitis media indications: } \\
{ }^{*} \text { If child is unable to tolerate oral } \\
\text { route } \\
{ }^{\wedge} \text { For cases of oral treatment } \\
\text { failure }\end{array}$} \\
\hline & $\begin{array}{l}50 \mathrm{mg} / \mathrm{kg} \text { intramuscularly for } \\
3 \text { consecutive days, with a } \\
\text { maximum of } 1,000 \mathrm{mg} \text { per dose }\end{array}$ & $1,000 \mathrm{mg}$ & \\
\hline
\end{tabular}

than age 2 years who have uncomplicated AOM. Intramuscular (IM) ceftriaxone is an acceptable first-line agent in a child who is unable to tolerate oral medications or who is suffering persistent emesis. Intramuscular ceftriaxone can be given as a single dose of $50 \mathrm{mg} / \mathrm{kg}$, though the patient should be followed closely as studies show that a second dose may be necessary 5 to 7 days later to prevent infection recurrence. The IM dose of ceftriaxone $50 \mathrm{mg} / \mathrm{kg}$ can also be given if treatment with other antibiotics fails to resolve the AOM (failure is defined as no improvement in the patient's condition 48 to 72 hours from treatment). In such cases, ceftriaxone is given in three consecutive doses. ${ }^{3,4,7}$

Wait-and-See Approach. Studies of patients whose AOM was confirmed via culture (19\% were positive for $S$ pneumoniae, $48 \%$ for $H$ influenza, and $78 \%$ for $M$ catarrhalis) showed bacterial clearance without anti- biotic intervention. ${ }^{4}$ Based on these findings, the 2013 revised AAP evidence-based clinical practice guidelines indicate an initial watching-and-waiting period combined with pain management for patients older than 6 months of age who are diagnosed with unilateral AOM in the absence of severe symptoms (ie, fever is lower than $102.2^{\circ} \mathrm{F}$ or patient has severe otalgia). ${ }^{4} \mathrm{~A}$ period of observation prior to treatment is also endorsed for children older than age 2 years who exhibit nonsevere symptomseven if they have bilateral disease. ${ }^{4}$

Conversely, all patients younger than age 6 months and all children with severe symptoms should be treated with antibiotics at diagnosis., ${ }^{3,4}$ The wait-andsee approach, recommends an observation period of 24 to 48 hours for children in the lower risk group prior to antibiotic administration. Delayed antibiotic administration can be performed by a physician 
in an office/ED follow-up or as a safety-net antibiotic prescription (SNAP) sent home with the family on the initial ED encounter. $^{2-4,8,9}$

\section{Case 1 Resolution}

Given this patient's unilateral and nonsevere symptoms (minor otalgia, fever $<102.2^{\circ} \mathrm{F}$ ), age older than 6 months, and no recent antibiotic use), she was treated with oral ibuprofen. At discharge, the parents were given a 10-day SNAP prescription of high-dose amoxicillin $(90 \mathrm{mg} / \mathrm{kg} / \mathrm{d}$, divided into two daily doses) and instructed to fill the prescription only if the patient's otalgia did not improve in 1 or 2 days.

\section{Case Scenario 2}

A 5-year-old boy was presented for evaluation by his parents, who stated that their son had been sick since he had started kindergarten in the fall. The patient had a 10-day history of cough, thick runny nose, and facial pain, and a 1-day history of new-onset fever and headache. His parents further noted that the patient had been seen by his pediatrician several times over the past week. At each of these visits, the pediatrician had informed them that their son had a virus.

Vital signs on examination were: BP, 100/60 mm Hg; heart rate (HR), 112 beats/ min; normal age-adjusted RR; and T, $102.6^{\circ} \mathrm{F}$. Oxygen saturation was $100 \%$ on room air. The patient did not appear toxic, his lungs were clear on auscultation, and there were no other clinical signs suggestive of meningitis. The otolaryngologic examination revealed bilateral thick mucoid drainage and visible edema and erythema of the nasal turbinates. The patient was noted to have some facial pain in the maxillary area bilaterally.

Questions to Guide the Work-Up: (1) Does the patient have a prolonged URI or pediatric sinusitis, and what differentiates the two conditions? (2) What sinuses are present in a 5-year-old patient? (3) What treatment modalities are available for sinusitis? (4) Is imaging of the sinuses helpful in confirming the diagnosis?

\section{Acute Bacterial Sinusitis}

Rhinosinusitis is an inflammation of the mucosal lining of the nasal passages and paranasal sinuses. Most cases occur secondary to a viral URI and resolve spontaneously in $99 \%$ of the pediatric population..$^{10,11}$

Acute bacterial sinusitis (ABS) is an inflammation of the same mucosal lining of the nasal passages secondary to bacterial overgrowth that lasts more than 10 days, with complete resolution by 30 days. ${ }^{12,13}$ When evaluating a pediatric patient for ABS, it is important to consider the sinus growth and development: If the sinus is not yet formed, it therefore cannot be the location of an ABS..$^{13}$ The ethmoid and maxillary sinuses are present at birth, aerated within 4 months of life, and are fully developed by age 12 years. The sphenoid sinuses begin development around age 3 years, are aerated by age 7 or 8 years, and are fully developed by age 18 to 20 years. The frontal sinuses begin development around age 8 years and are aerated and fully developed by age 12 to 15 years. ${ }^{10,13,14}$ While most guidelines focus on children older than age 1 year (due to very small infantile sinuses), ABS does occur in children younger than age 1 year. ${ }^{12,14}$

\section{Signs and Symptoms}

Differentiation between a viral URI/rhinosinusitis and ABS is a challenge and can be based upon severity of symptoms as well as length of illness. Symptoms of ABS are typically present and persistent for more than 10 days, without improvement. Continuing illness and worsening of symptoms are identifying features of ABS given most viral URIs gradually resolve within a 10day timeframe. Other common symptoms include milky/thick nasal discharge, fever, predominantly nocturnal cough, and headache. Other less common symptoms include facial pain, toothache, malodorous breath, and periorbital edema. On physical examination, erythema and edema of the turbinates, as well as reproducible pain over aerated sinuses, are suggestive of ABS. ${ }^{10-14}$ 


\section{Diagnosis}

In the acute care setting, diagnosis of ABS should be clinical in nature. Neither imaging nor laboratory work-up is generally required secondary to their poor diagnostic specificity for ABS. The bacteria involved in ABS are similar to those associated with AOM, with $S$ pneumonia, nontypeable $H$ influenza, and M catarrhalis being the predominant organisms. ${ }^{10-15}$

\section{Treatment and Management}

Treatment of ABS is generally recommended once the diagnosis is made, though this is based largely on expert opinion as there are limited RCTs available. ${ }^{13}$ However, available studies do show a more rapid improvement in children on antibiotic therapy than those on placebo. ${ }^{15,16}$

Antibiotic Therapy. Amoxicillin remains the antimicrobial agent of choice for firstline treatment of uncomplicated ABS forsituations in which antimicrobial resistance is not suspected. In communities with a high prevalence of nonsusceptible $S$ pneumoniae ( $>10 \%$, including intermediate- and high-level resistance), treatment may be initiated at 80 to $90 \mathrm{mg} / \mathrm{kg} / \mathrm{d}$ in two divided doses, with a maximum of $2 \mathrm{~g}$ per dose.

Patients presenting with moderate to severe illness, as well as those who are younger than 2 years, attend childcare, or have recently been treated with an antimicrobial, may receive high-dose amoxicillin-clavulanate as initial therapy given the elevated beta-lactamase production of the common bacteria that cause ABS.

Second-line alternatives include azithromycin, cefdinir, and sulfamethoxizoletrimethoprim (Table 1). There are data to suggest higher rates of decreased susceptibility of $S$ pneumonia and $H$ influenza to third-generation cephalosporins, and the addition of clindamycin may be warranted when utilizing those medications. Treatment is recommended for 10 to 14 days, though improvement should be noted within 1 to 3 days. ${ }^{10-12,14-17}$
Adjuvant Therapy. Additional therapies include nasal irrigation, decongestants, antihistamines, and intranasal steroids; however, there are only anecdotal reports of their efficacy in providing symptom relief. Therefore, there are insufficient evidencebased data to support or refute the role of these adjuvant therapies in treating pediatric patients with $\mathrm{ABS}{ }^{9}{ }^{9,13}$

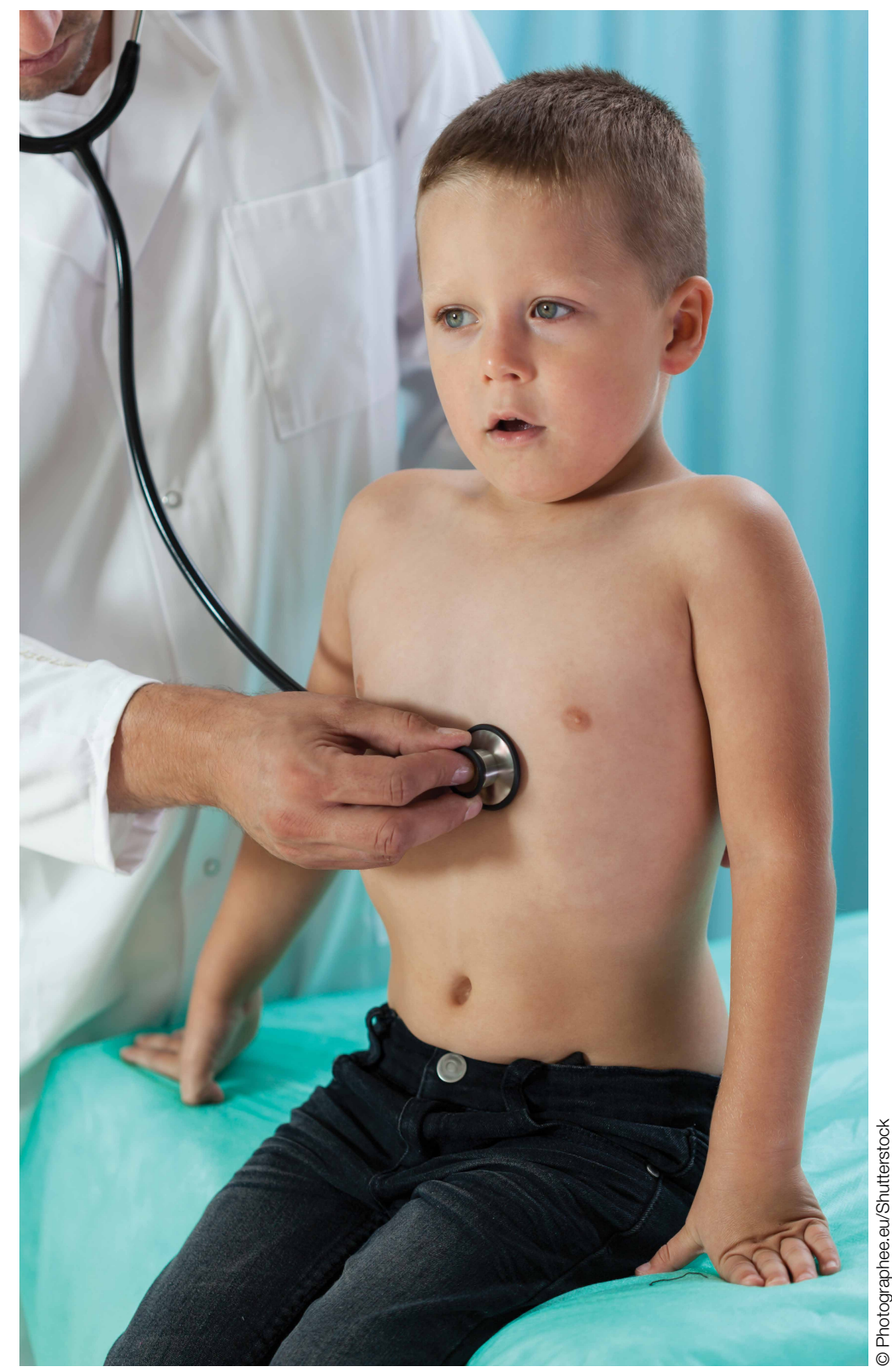




\section{Case 2 Resolution}

The prolonged duration and severity of symptoms (high fever and headache) and the gradual worsening of the clinical course (ie, late-onset fever) in this patient all suggest ABS rather than a simple prolonged URI. The physical examination findings of inflamed turbinates and facial pain further increase the specificity for ABS. The patient was started on oral amoxicillin-clavulanate with planned treatment for 14 days. At discharge, his parents were instructed to followup with the patient's pediatrician in 3 days to ensure a degree of clinical resolution.

\section{Case Scenario 3}

A 4-year-old boy was presented by his parents for evaluation of a 2-day history of a persistent and unimproved sore throat. The patient's mother indicated that the child's oral $\mathrm{T}$ upon returning home earlier from preschool was $101.2^{\circ} \mathrm{F}$. She further noted that her 17-month-old daughter and 8-yearold son also experienced similar symptoms which had self-resolved. Triage vital signs were: $\mathrm{T}, 100.8^{\circ} \mathrm{F}$, orally; $\mathrm{BP}, \mathrm{HR}$, and RR were all within normal limits. Oxygen saturation was $100 \%$ on room air.

On physical examination, the child was noted to have anterior cervical lymph nodes bilaterally and an erythematous oropharynx with exudate noted on both tonsils. There were no cutaneous abnormalities, nasal edema, erythema, or drainage. Based on the clinical examination, the EP was suspicious for SP.

Questions to Guide the Work-Up: (1) Is SP diagnosed based on clinical findings alone in this patient's age group? (2) At what age in the pediatric population is it appropriate to perform a rapid streptococcal antigen test? (3) Are there medications other than antibiotics that are beneficial in treating symptomatic SP?

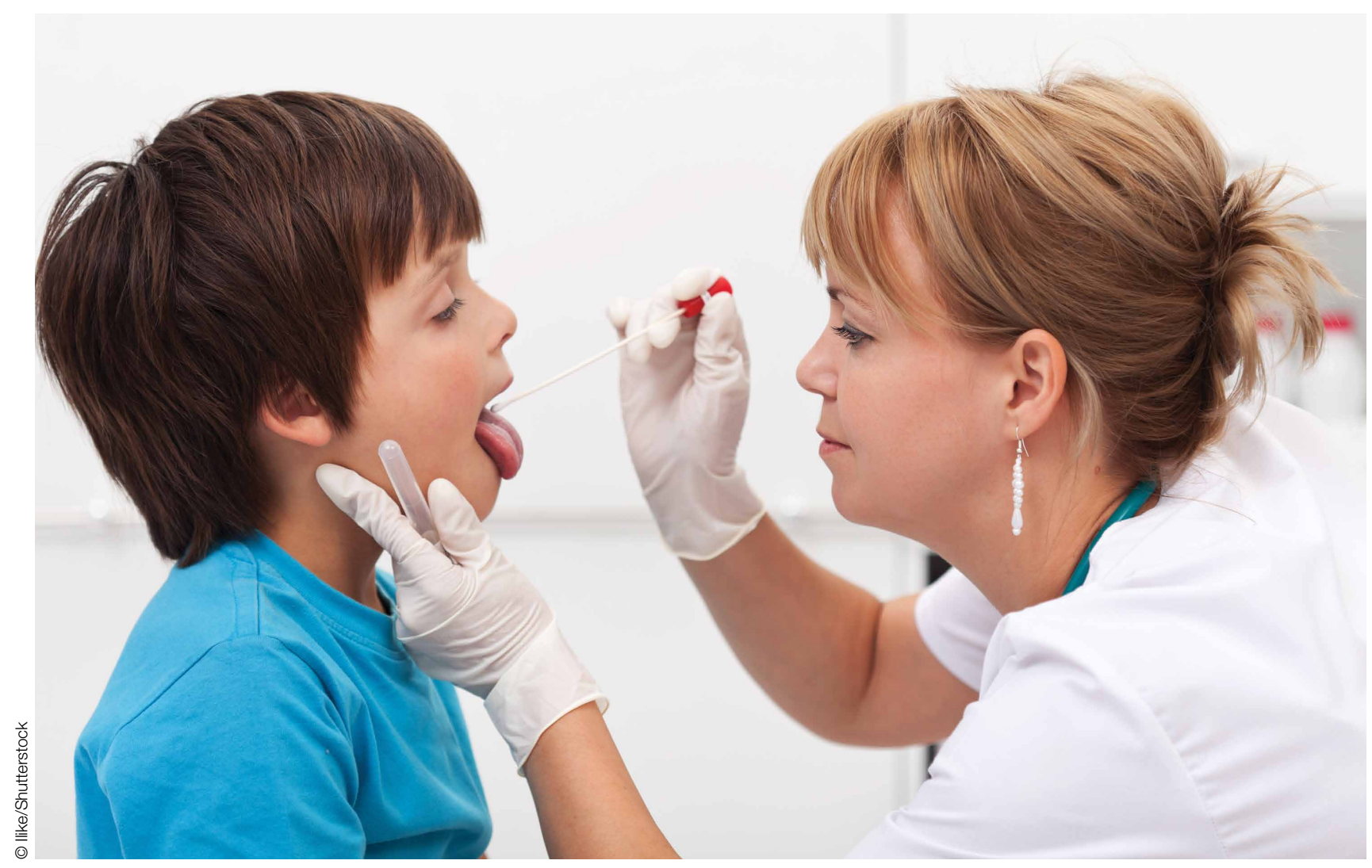




\section{Streptococcal Pharyngitis}

Streptococcal pharyngitis is a clinical condition caused by group A beta-hemolytic $S$ pyogens. This bacterium is responsible for multiple conditions, including pharyngitis, skin infections, poststreptococcal glomerulonephritis, and rheumatic fever, as well as invasive syndromes. (This case focuses solely on SP).

Pharyngitis can occur secondary to a viral or bacterial infection, and SP is the most common cause of pediatric bacterial pharyngitis. It is estimated that children aged 5 to 15 years are more commonly diagnosed with SP, although approximately $24 \%$ of children younger than age 5 years with pharyngitis symptoms will be ultimately diagnosed with SP.

\section{Signs and Symptoms}

Typical symptoms include fever, pharyngitis, generalized abdominal pain, nausea, vomiting, headache, and absence of viral URI symptoms (eg, cough, nasal discharge). However, younger patients with SP may have clinical findings of prolonged nasal drainage and excoriated nares. Examination findings may include swollen and tender anterior cervical lymph nodes; generalized edema and erythema of the posterior pharynx; tonsillar exudates; and palatal petechiae.

\section{Diagnosis}

Centor Criteria. The Centor criteria were developed to assist practitioners in identifying patients with potential SP. Criteria for patients older than age 15 years include fever, absence of cough, tonsillar exudates, and tender anterior cervical lymphadenopathy. A modified Centor criteria was later established to include children older than age 5 years, with children between ages 5 and 15 years being the fifth variable in the modified score. In general, patients with a score of 4 or 5 (presence of each variable $=1$ point) are most likely to test positive for SP on rapid antigen testing (RAT) or culture. ${ }^{18-20}$
Swab, Rapid Antigen Testing, and Culture. Swabbing the throat and RAT and/or culture should be performed in most children with suspected SP because the clinical features alone do not reliably discriminate SP from viral pharyngitis. Rapid antigen testing is only specific for group A beta-hemolytic streptococcal species, which is the only streptococcal species that is routinely treated with antibiotics in the setting of acute pharyngitis. It is unlikely for a patient with a score of 0 or 1 to have SP, and several sources suggest neither testing nor treating this cohort, but rather to consider an alternative diagnosis. ${ }^{18-20}$

Within the population of children and young adolescents, due to a RAT sensitivity of $70 \%$ to $90 \%$, a negative result should always be backed-up by a throat culture, and treatment initiated if results of the culture are later found to be positive. As the current generation of RAT tests have a high specificity, a positive RAT does not necessitate a back-up culture, and treatment is indicated without further investigation..$^{19,20}$

Routine RAT is not recommended in children younger than age 3 years as patients in this age group are at low-risk of developing rheumatic fever. One notable exception for these very young children would be if there are siblings in the home with confirmed SP, in which case, RAT should be considered in the clinical context of SP. ${ }^{21}$ Adolescents over age 15 years are another cohort with a low likelihood of developing rheumatic fever, though they can develop other poststreptococcal complications, such as glomerulonephritis.

The US Centers for Disease Control and Prevention/American Academy of Family Practitioners (AAFP) guidelines suggest that pharyngitis in older adolescents can be approached in a similar fashion to adults, with empiric therapy for a Centor score of 3 or 4, RAT (without the need for follow-up culture) for Centor score of 2, and neither testing nor treating patients with a score of 0 or $1 .^{19}$ 
Table 2. Recommended Antibiotic Therapy for Streptococcal Pharyngitis ${ }^{19-22}$

\begin{tabular}{|c|c|c|c|c|}
\hline Drug & Route & Dose & Maximum Dosage & Length of Treatment \\
\hline Penicillin V & Oral & $\begin{array}{l}250 \mathrm{mg} \text { twice a day in } \\
\text { patients weighing }<27 \mathrm{~kg} \\
500 \mathrm{mg} \text { twice a day } \\
\text { to three times a day in } \\
\text { patients weighing }>27 \mathrm{~kg}\end{array}$ & & 10 days \\
\hline Amoxicillin & Oral & $\begin{array}{l}50 \mathrm{mg} / \mathrm{kg} / \mathrm{d} \\
\text { once a day or divided } \\
\text { twice a day }\end{array}$ & $1,000 \mathrm{mg} / \mathrm{d}$ & 10 days \\
\hline Benzathine penicillin $G$ & Intramuscular & $\begin{array}{l}600,000 \cup \text { in patients } \\
\text { weighing }<27 \mathrm{~kg} \\
1,200,000 \cup \mathrm{in} \text { patients } \\
\text { weighing }>27 \mathrm{~kg}\end{array}$ & & Once \\
\hline Cephalexin & Oral & $\begin{array}{l}40 \mathrm{mg} / \mathrm{kg} / \mathrm{d} \text { divided } \\
\text { twice a day }\end{array}$ & $\begin{array}{l}1,000 \mathrm{mg} / \mathrm{d} \\
\text { (500 mg per dose) }\end{array}$ & 10 days \\
\hline Azithromycin & Oral & $12 \mathrm{mg} / \mathrm{kg} / \mathrm{d}$ & $500 \mathrm{mg} / \mathrm{d}$ & $\begin{array}{l}5 \text { days } \\
\text { (Note: Dosing strategy } \\
\text { is different than is } \\
\text { typical for this drug) }\end{array}$ \\
\hline Clindamycin & Oral & $\begin{array}{l}21 \mathrm{mg} / \mathrm{kg} / \mathrm{d} \text { divided } \\
\text { three times a day }\end{array}$ & $\begin{array}{l}900 \mathrm{mg} / \mathrm{d} \\
\text { (300 mg per dose) }\end{array}$ & 10 days \\
\hline
\end{tabular}

\section{Treatment and Management}

Streptococcal pharyngitis is treated mainly to prevent the poststreptococcal complications of rheumatic fever, though it will not prevent poststreptococcal glomerulonephritis. Treatment of SP also facilitates resolution of symptoms and return to baseline activities.

Antibiotic Therapy. Patients who have a positive RAT or a follow-up throat culture positive for group A streptococcus should be given antibiotics. The gold standard treatment is penicillin $\mathrm{V}$ orally for 10 days. Other medication choices include amoxicillin orally for 10 days or a single IM dose of benzathine penicillin G. For penicillinallergic patients, alternative regimens include oral azithromycin, cephalexin, and clindamycin (Table 2). ${ }^{19-22}$

Corticosteroid Therapy. The use of cortico- steroids for symptom control of SP in pediatric patients is controversial. Although the Infectious Disease Society of America does not recommend corticosteroid therapy in the treatment of SP, several studies show such therapy (namely dexamethasone), improves pain in children and adolescents diagnosed with SP, but without significant change to the overall disease course. $^{21,23-26}$

\section{Case 3 Resolution}

The patient had a modified Centor criteria score of 4 , as well as siblings with similar symptoms. In following current guidelines, the EP performed a RAT and back-up culture. The RAT was negative in the ED, but the back-up culture was subsequently positive, and the child was started on a 10day course of oral amoxicillin. 


\section{Conclusion}

When evaluating pediatric patients presenting with ENT signs and symptoms such as ear pain and erythema, fever, sore throat, nasal congestion and discharge, a thorough physical examination and history-taking-including recent illness of any siblings-along with testing when indicated, is essential to guide the diagnosis and determine appropriate treatment and management. In addition to administering antibiotic therapy when such is warranted, the EP should provide appropriate analgesia to manage the patient's pain and assure relief prior to discharge.

\section{References}

1. Rosenfeld RM, Shin JJ, Schwartz SR, et al. Clinical practice guideline: otitis media with effusion (Update). Otolaryngol Head Neck Surg. 2016;154(1 Suppl):S1-S41. doi:10.1177/0194599815623467.

2. Acute Otitis Media Guideline Team, Cincinnati Children's Hospital Medical Center. Evidence-based care guideline for medical management of acute otitis media in children 2 months to 13 years of age. http://f.i-md.com/medinfo/material/4f4/4eb132ba 44ae4ffe12a814f4/4eb132d744ae4ffe12a814f7.pdf. August 2006. Accessed December 29, 2016.

3. Nesbit CE, Powers MC. An evidence-based approach to managing acute otitis media. Pediatr Emerg Med Pract. 2013;10(4):1-26; quiz 26-27.

4. Lieberthal AS, Carroll AE, Chonmaitree T, et al. The diagnosis and management of acute otitis media. Pediatrics. 2013;131(3):e964-e999. doi:10.1542/ peds.2012-3488.

5. American Academy of Family Physicians; American Academy of Otolaryngology-Head and Neck Surgery; American Academy of Pediatrics Subcommittee on Otitis Media With Effusion. Otitis media with effusion. Pediatrics. 2004:113(5):1412-1429.

6. US Food and Drug Administration Web site. FDA: Use only approved prescription ear drops. http:// www.fda.gov/ForConsumers/ConsumerUpdates/ucm453087.htm. Updated July 10, 2015. Accessed December 15, 2016.

7. Sack F. An evidence based approach to the management of uncomplicated acute otitis media in children. Int Pediatrics. 2005;20(1):44-46.

8. Johnson NC, Holger JS. Pediatric acute otitis media: the case for delayed antibiotic treatment J Emerg Med. 2007;32(3):279-284. doi:10.1016/j. jemermed.2006.07.029.

9. Spiro DM, Tay KY, Arnold DH, Dziura JD, Baker MD, Shapiro ED. Wait-and-see prescription for the treatment of acute otitis media: a randomized controlled trial. JAMA. 2006;296(10):1235-1241. doi:10.1001/ jama.296.10.1235.

10. Brook I. Management of acute rhinosinusitis in pediatric patients. Pediatr Emerg Med Pract. 2012;9(5):1-24

11. Ferdman RM, Linzer JF Jr. The runny nose in the emergency department: rhinitis and sinusitis. Clin Pediatr Emerg Med. 2007;8(2):123-130.

12. Acute Bacterial Sinusitis Guideline Team, Cincinnati Children's Hospital Medical Center: Evidence-based care guideline for medical management of acute bac- terial sinusitis in children 1 through 18 years of age. http://www.antibioticos.msssi.gob.es/PDF/sinusitisguideline.pdf. July 7, 2006. Accessed December 29, 2016

13. Holt KR, Murdoch Cuenca M, Cuenca PJ, Johnston GM. acute pediatric sinusitis and "the 10-day rule." Pediatr Emerg Med Pract. 2006;3(2):1-16.

14. American Academy of Pediatrics. Subcommittee on Management of Sinusitis and Committee on Quality Improvement. Clinical practice guideline: management of sinusitis. Pediatrics. 2001;108(3):798-808.

15. Wald ER, Nash D, Eickhoff J. Effectiveness of amoxicillin/clavulanate potassium in the treatment of acute bacterial sinusitis in children. Pediatrics. 2009;124(1):9-15. doi:10.1542/peds.2008-2902.

16. Arroll B, Kenealy T. Are antibiotics effective for acute purulent rhinitis? Systematic review and meta-analysis of placebo controlled randomised trials. BMJ. 2006;333(7562):279. doi:10.1136/ bmj.38891.681215.AE.

17. McQuillan L, Crane LA, Kempe A. Diagnosis and management of acute sinusitis by pediatricians. Pediatrics. 2009;123(2):e193-e198.

18. Singer JI, Fontanette R. Recognizable and suspected group A beta-hemolytic streptococcal syndromes. Pediatr Emerg Med Rep. 2010;15(11):129-144.

19. Weglowski J. An evidence-based approach to the evaluation and treatment of pharyngitis in children. Pediatr Emerg Med Pract. 2011;8(12):1-28.

20. Gerber MA, Baltimore RS, Eaton CB, et al. Prevention of rheumatic fever and diagnosis and treatment of acute Streptococcal pharyngitis: a scientific statement from the American Heart Association Rheumatic Fever, Endocarditis, and Kawasaki Disease Committee of the Council on Cardiovascular Disease in the Young, the Interdisciplinary Council on Functional Genomics and Translational Biology, and the Interdisciplinary Council on Quality of Care and Outcomes Research: endorsed by the American Academy of Pediatrics. Circulation. 2009;119(11):1541-1551. doi:10.1161/CIRCULATIONAHA.109.191959.

21. Shulman ST, Bisno AL, Clegg HW, et al. Clinical practice guideline for the diagnosis and management of group A streptococcal pharyngitis: 2012 update by the Infectious Diseases Society of America. Clin Infect Dis. 2012;55(10):1279-1282. doi:10.1093/cid/ cis847.

22. Clegg HW, Ryan AG, Dallas SD, et al. Treatment of streptococcal pharyngitis with once-daily compared with twice-daily amoxicillin: a noninferiority trial. Pediatr Infect Dis J. 2006;25(9):761-767. doi:10.1097/01.inf.0000235678.46805.92.

23. Bulloch B, Kabani A, Tenenbein M. Oral dexamethasone for the treatment of pain in children with acute pharyngitis: a randomized, double-blind, placebocontrolled trial. Ann Emerg Med. 2003;41(5):601608. doi:10.1067/mem.2003.136.

24. Niland ML, Bonsu BK, Nuss KE, Goodman DG. A pilot study of 1 versus 3 days of dexamethasone as add-on therapy in children with streptococcal pharyngitis. Pediatr Infect Dis J. 2006;25(6):477-481. doi:10.1097/01.inf.0000219469.95772.3f.

25. Wei JL, Kasperbauer JL, Weaver AL, Boggust AJ. Efficacy of single-dose dexamethasone as adjuvant therapy for acute pharyngitis. Laryngoscope. 2002;112(1):87-93. doi:10.1097/00005537200201000-00016.

26. Hayward G, Thompson M, Heneghan C, Perera R, Del Mar C, Glasziou P. Corticosteroids for pain relief in sore throat: systematic review and meta-analysis. BMJ. 2009;339:b2976. doi:10.1136/bmj.b2976. 